\title{
Separation of Amino Acids Based on Thin-Layer Chromatography by a Novel Quinazoline Based Anti-Microbial Agent
}

\author{
Supriti Sen*, Sandipan Sarkar*, Pijush Kundu, Subrata Laskar \\ Department of Chemistry, The University of Burdwan, Golapbag, India \\ Email: "sssensupriti@gmail.com
}

Received March 14, 2012; revised May 30, 2012; accepted June 9, 2012

\begin{abstract}
A newly designed quinazoline based compound, 6-pyridin-2-yl-5,6-dihydro-benzo[4,5]imidazo[1,2-c] quinazoline (PDBIQ) has shown the ability for the easy detection of nineteen amino acids on thin-layer chromatography plates as a spray reagent. This new reagent enabled to produce various distinguishable colors with amino acids with different $R_{F}$ values. The detection limits and the binding ability of PDBIQ with amino acids have been calculated. PDBIQ is also able to detect aminoacids from hydrolised seed protein. The title compound also exhibited profound inhibitory action against some gm $(+\mathrm{ve})$ and gm $(-\mathrm{ve})$ bacterial organisms. This paper deals with synthesis, spectroscopic application and biological evaluation of the organic moity.
\end{abstract}

Keywords: Thin-Layer Chromatography; Amino Acid; Ninhydrin; Binding Constant; Antimicrobial Property

\section{Introduction}

The chemistry of Quinazolines class compounds are very promising because it shows wide spectram of biological activity like analgesic and anti-inflammatoryanti, antimicrobial, antihypertensive, anticancer [1-4] etc. activities. Because of such enriched chemistry we are interested in evaluation and application of quinazoline compound. The detection or identification of amino acids is extremely important in biomedical and biochemical analysis for the evaluation of protein structure as the amino acids are the monomeric units of proteins; these amino acids are used by cells for protein biosynthesis, and also exist in the free state in numerous natural products (seeds and leaves) and as the C-terminal determination of degraded proteins. Several specific and non-specific reagents have been reported on thin-layer chromatography (TLC) plates [5-10]. Such identification is the most well-known reagent is ninhydrin which is widely used for its remarkable high sensitivity. But, it produces same purple/violet color with all amino acids except proline and hydroxyproline. An attempt has been established to overcome this color problem using 6-pyridin-2-yl-5,6-dihydro-benzo[4,5]imidazo[1,2-c] quinazoline (PDBIQ)-ninhydrine as a new reagent which affords distinguishable colors with twenty two protein amino acids and, enables convenient and easy detection of such compounds on silica gel " $G$ " for TLC with very good sensi-

${ }^{*}$ Corresponding authors. tivity (detection limit between $0.1-0.5 \mu \mathrm{g}$ at cold condition and $0.05-0.2 \mu \mathrm{g}$ after heating).

Herein we report an account on the systematic application of a newly designed quinazoline based spraying reagent (PDBIQ) for the detection of amino acids at trace level along with the equilibrium binding constant (k) with different amino acids and bio-activity test against some gm $(+v e)$ and gm $(-v e)$ bacterial organisms.

\section{Experimental}

\subsection{Apparatus and Materials Used}

Thin layer chromatography plates $(20 \times 20 \mathrm{~cm}$, thickness $0.1 \mathrm{~mm}$ ) were prepared using silica gel "G" (Merck, India) and a Unoplan coating apparatus (Shaudon, London, UK). Sample solutions were spotted on to the plates by means of a graduated micropipette $(5.0 \mu \mathrm{L})$. Electronic absorption spectra were recorded on a JASCO UV-Vis/NIR spectrophotometer model V-570.

Pyridine-2-carboxylaldehyde and 2-(2-aminophenyl) benzimidazole for the synthesis of the title compound (PDBIQ) were purchased from Aldrich. Standard amino acids and ninhydrin were procured from Sigma (USA) and $n$-propanol from Merck (India). All other chemicals and solvents were used as received. The spraying reagent, 6-pyridin-2-yl-5,6-dihydro-benzo[4,5]imidazo[1,2-c]quinazoline (PDBIQ) was synthesized in our laboratory as described below. 


\subsection{Synthesis of 6-Pyridin-2-yl-5, 6-dihydro-benzo[4,5]imidazo[1,2-c] quinazoline (PDBIQ)}

An ethanolic solution of 2-(2-aminophenyl)benzimidazole, $(2.09 \mathrm{~g}, 10.0 \mathrm{mmol})$ was added to pyridine-2-carboxylaldehyde $(1.07 \mathrm{~g}, 10.0 \mathrm{mmol})$ in ethanol $(25.0 \mathrm{~mL})$ at room temperature. Then this mixture was allowed to reflux for $4.0 \mathrm{~h}$. The white colored crystalline precipitate of the compound (PBBIQ) was obtained from the yellow colored solution through slow evaporation of the solvent in few days. The single crystals of L suitable for X-ray crystallography were also obtained from the methanolic solution of the white colored product on slow evaporation at room temperature. These single crystals have been used in the experiments.

$\mathrm{C}_{19} \mathrm{H}_{14} \mathrm{~N}_{4}$ : Anal. Found: $\mathrm{C}, 76.56 ; \mathrm{H}, 4.75 ; \mathrm{N}, 18.49$; Calc.: C, 76.48; H, 4.73; N, 18.78 . m.p. $231^{\circ} \mathrm{C} \pm 1{ }^{\circ} \mathrm{C}$, MS: $[\mathrm{M}+\mathrm{H}]^{+}, \mathrm{m} / \mathrm{z}, 299.34 ; \mathrm{IR}\left(\mathrm{KBr}, \mathrm{cm}^{-1}\right): v_{\mathrm{N}-\mathrm{H}}, 2950, v_{\mathrm{C}=\mathrm{N}}$, 1477;. ${ }^{1} \mathrm{H}$ NMR $\left(\delta\right.$, ppm in dmso-d $\left.{ }_{6}\right): 8.437(\mathrm{~d}, 1 \mathrm{H}, \mathrm{j}=$ 3.9); 7.906 (d, 1H, j = 7.2); 7.768 - 7.697 (m, 2H); 7.631 $(\mathrm{d}, 1 \mathrm{H}, \mathrm{j}=7.2) ; 7.351-7.096(\mathrm{~m}, 7 \mathrm{H}) ; 6.853-6.769(\mathrm{~m}$, 2H); Yield: $90 \%$.

\subsection{Detection of Amino Acids on TLC Plates}

Standard solutions $(1 \mathrm{mg} / \mathrm{ml})$ of amino acids were prepared in $0.01 \mathrm{M}$ phosphate buffer ( $\mathrm{pH} 8.0$ ) and spotted on the TLC plates. Spotting volume was always $1 \mu \mathrm{L}$; the solutions were diluted approximately when necessary. Plates were air-dried and subjected to TLC using $n$-propanolwater, $70+30(\mathrm{v} / \mathrm{v})$ as mobile phase. After development plates were dried and sprayed with $0.01 \%$ PDBIQ in ethyl alcohol (Reagent 1) and again dried in air for complete evaporation of solvent. The plates were then sprayed with $0.25 \%$ ninhydrin in acetone (Reagent 2), dried in air and colors were noted Table 1. The plates were then heated at $110^{\circ} \mathrm{C}$ for $10 \mathrm{~min}$ in an oven and the colors were recorded again. Colors were always observed visually. Detection limits for the amino acids [11] after use of ninhydrin alone are also given in Table 1.

Table 1. Formation of color by amino acids using PDBIQ and ninhydrin reagents, detection limits for these reagents and for ninhydrin alone on silica gel with $n$-propanol-water 70:30 as mobile phase.

\begin{tabular}{|c|c|c|c|c|c|}
\hline \multirow{2}{*}{ Amino acids } & \multicolumn{2}{|c|}{ Cold condition } & \multicolumn{2}{|c|}{ After final heating } & \multirow{2}{*}{$\begin{array}{l}\text { Detection limit for ninhydrin } \\
\qquad(\mu \mathrm{g})\left(\mathrm{R}_{\mathrm{F}}\right)\end{array}$} \\
\hline & Observed colors & Detection limit $(\mu \mathrm{g})$ & Observed colors & Detection limit $(\mu \mathrm{g})$ & \\
\hline Glycine & Deep orange & 0.5 & Deep pink & 0.1 & $0.01(0.03)$ \\
\hline Alanine & Pinkish violet & 0.1 & Light pink/milky pink & 0.1 & $0.009(0.22)$ \\
\hline Valine & Reddish pink & 0.1 & Reddish pink & 0.05 & $0.01(0.14)$ \\
\hline Leucine & Bluish violet & 0.5 & Violetish pink & 0.1 & $0.01(0.09)$ \\
\hline Isoleucine & Very light violet & 1.0 & Light violet & 0.1 & $0.20(0.32)$ \\
\hline Serine & Deep pink & 0.1 & Deep bluish pink & 0.1 & $0.008(0.38)$ \\
\hline Threonine & Yellowish orange/ivory & 0.5 & Yellowish pink/candy & 0.1 & $0.05(0.28)$ \\
\hline Aspartic acid & Yellowish violet & 0.2 & Greyish violet & 0.1 & $0.10(0.12)$ \\
\hline Aspargine & Light yellow/pale cream & 1.0 & Greyish yellow & 0.1 & $0.10(0.45)$ \\
\hline Glutamic acid & Light violet & 0.5 & Light violet & 0.1 & $0.04(0.33)$ \\
\hline Glutamine & Light violet & 0.5 & Light violet & 0.2 & $0.10(0.38)$ \\
\hline Lysine & Reddish violet & 0.2 & Brick red & 0.1 & $0.005(0.42)$ \\
\hline Histidine & Yellowish violet & 0.1 & Yellowish pink/petal & 0.1 & $0.05(0.18)$ \\
\hline Arginine & Light pink/mauve & 0.5 & Pink & 0.1 & $0.01(0.05)$ \\
\hline Phenyl alanine & Orangish violet & 1.0 & Greyish pink & 0.2 & $0.05(0.58)$ \\
\hline Tyrosine & Light violet & 1.0 & Light pink & 0.1 & $0.03(0.51)$ \\
\hline Tryptophan & Greyish violet & 0.5 & Pinkish violet & 0.1 & $0.05(0.55)$ \\
\hline Cysteine & Yellowish violet & 2.0 & Pinkish violet & 1.0 & $0.02(0.41)$ \\
\hline Cystine & Very light pink & 2.0 & Light pink & 1.0 & $0.01(0.35)$ \\
\hline Methionine & Lilac/bluish violet & 0.5 & Bluish violet & 0.2 & $0.01(0.48)$ \\
\hline Proline & Light yellow/off white & 1.0 & Grey/beige & 0.2 & $0.10(0.22)$ \\
\hline Hydroxy proline & Pinkish violet & 0.2 & Yellowish brown & 0.1 & $0.05(0.34)$ \\
\hline
\end{tabular}




\subsection{Determination of Equilibrium Binding Constant}

This experiment was carried out at $\mathrm{pH} 8.0$ (phosphate buffer) with a standard solutions $\left(1 \times 10^{-5}(\mathrm{M})\right)$ of aminoacids. The solution of PDBIQ was prepared in ethanol with a concentration of fifty times higher than that of the amino acids [12]. Absorption titration experiment (as given in Figure 1 as example) was performed varying the amino acids concentration and concentration of the PDBIQ was kept constant. In order to illustrate the binding strength of PDBIQ with different amino acids, the equilibrium binding constant $(\mathrm{k})$ was determined from the spectral titration data using the following equation.

$$
\begin{aligned}
& {[\text { Aminoacid }] /\left(\varepsilon_{a}-\varepsilon_{f}\right) } \\
= & {[\text { Aminoacid }] /\left(\varepsilon_{b}-\varepsilon_{f}\right) 1 /\left[\mathrm{k}\left(\varepsilon_{b}-\varepsilon_{f}\right)\right] }
\end{aligned}
$$

$\varepsilon_{f}$ and $\varepsilon_{b}$ represent the extinction coefficients for the free and fully bound amino acids complex. $\varepsilon_{\mathrm{a}}$ is the extinction coefficients during each addition of amino acids. The [Aminoacid] $/\left(\varepsilon_{a}-\varepsilon_{f}\right)$ plot against [Aminoacid] gave a linear relationship as shown in (Figure 2) for cysteine for example. From these graphical plots, the slope of the straight lines was determined to calculate the binding constants $(\mathrm{k})$ for the corresponding amino acids with PDBIQ.

\subsection{Application-Detection of Amino Acids Present in $A$. excelsa Seed Protein}

The seed protein $(5.0 \mathrm{mg})$ was hydrolysate with $8 \mathrm{~mol} \cdot \mathrm{L}^{-1}$ $\mathrm{HCl}$ in an evacuated sealed glass tube for $24 \mathrm{~h}$ at $110^{\circ} \mathrm{C}$ in a temperature controlled oven. Then the hydrolysate was filtered and excess $\mathrm{HCl}$ was removed under reduced pressure at $40^{\circ} \mathrm{C}-50^{\circ} \mathrm{C}$. Traces of $\mathrm{HCl}$ (if any) was removed from the thin film of hydrochlorides of amino acids, by placing it in a vacuum desiccator over solid anhydrous $\mathrm{KOH}$ for $36 \mathrm{~h}$. Finally, it was dissolved in $1 \mathrm{~mL} \mathrm{10 \%} \mathrm{n}$ propanol. The finally obtained protein hydrolysate and

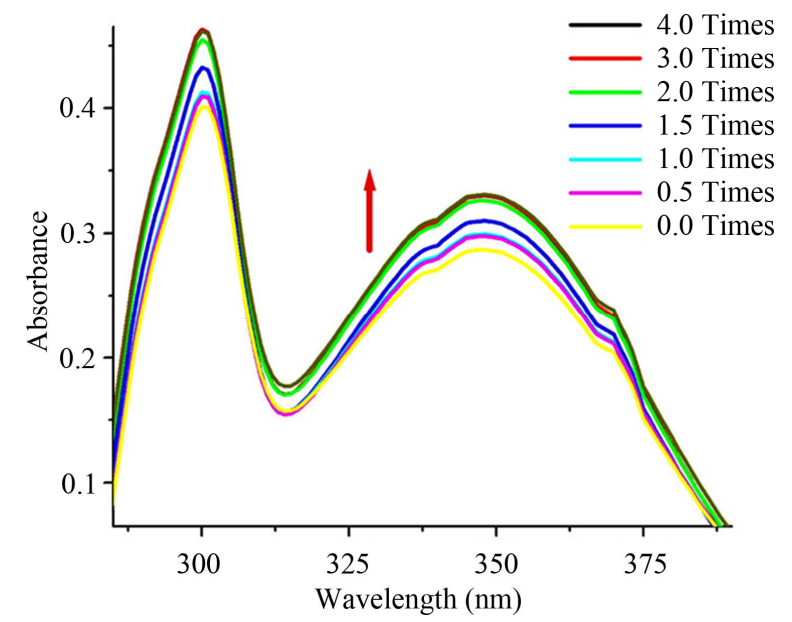

Figure 1. Electronic spectral titration of PDBIQ with cysteine.

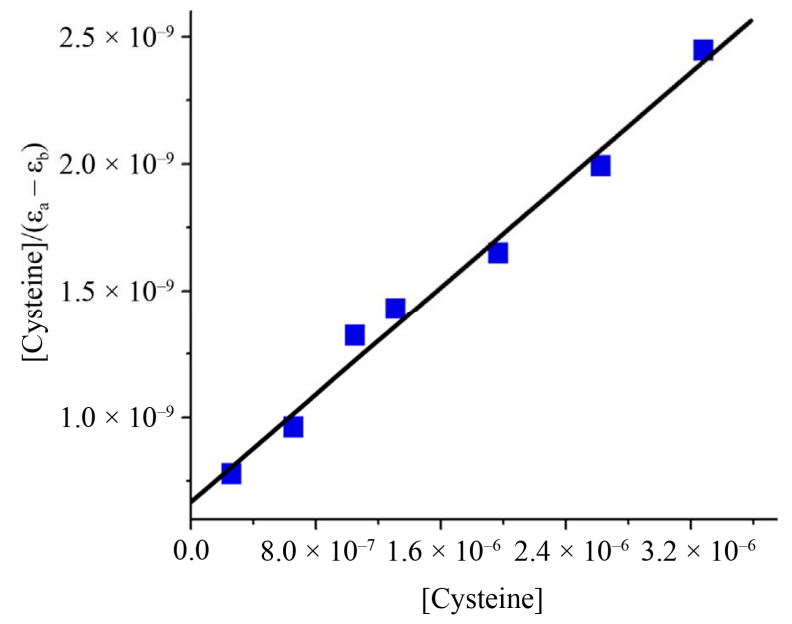

Figure 2. Plot of $[$ Cysteine $] / \varepsilon_{\mathrm{a}}-\varepsilon_{\mathrm{b}}$ vs. [Cysteine] for the absorption titration to determine binding constant.

amino acid standards were spotted on a TLC plate as above said with $n$-propanol-water 70:30 (v/v) as mobile phase. The plates were then dried, sprayed with a with $0.01 \%$ 6-pyridin-2-yl-5,6-dihydro-benzo[4,5]imidazo[1,2-c]quinazoline (PDBIQ) in ethanol (Reagent 1), air dried, heated to $110^{\circ} \mathrm{C}$ for $10 \mathrm{~min}$, then sprayed with $0.25 \%$ ninhydrin solution (Reagent 2 ) in acetone. The plates were again air dried and the colors were noted. Finally, the plates were again heated to $110^{\circ} \mathrm{C}$ for $10 \mathrm{~min}$ and colors noted again. From the observed colors of the amino acids (both seed protein hydrolysate and amino acid standards) and also by comparing $\mathrm{R}_{\mathrm{F}}$ values with those of the amino acid standards, it was possible to identify fourteen amino acids present in the seed protein of $A$. excelsa.

\subsection{Inhibitory Test with PDBIQ Reagent}

Antimicrobial testing was performed by cup plate method [13]. All cultures were routinely maintained on NA (nutrient agar) and incubated at $37^{\circ} \mathrm{C}$. The inoculums of bacteria were performed by growing the culture in NA broth at $37^{\circ} \mathrm{C}$ for overnight. $27 \mathrm{~mL}$ of molten agar was added to sterile Petri dishes and allowed to solidify for $1 \mathrm{~h}$. The bacterial suspensions $\left(10^{7}\right.$ cell $\left./ \mathrm{mL}\right)$ were spread uniformly on the top of the agar medium by a sterilized glass spreader. Six millimetre wide bores were made on the agar using a borer. The solutions of PDBIQ (1000 mg/mL) were added into each of the bores using a sterile tip with micropipette. The plates were then incubated at $37^{\circ} \mathrm{C}$ for $24 \mathrm{~h}$. The fungal strains were grown and maintained on Sabouraud glucose agar plates. The plates were incubated at $26^{\circ} \mathrm{C}$ for $72 \mathrm{~h}$. The degree of inhibition zone formed against some gm (+ve) and gm (-ve) bacterial organisms. The zone of the clearance around each bore after the incubation period confirms the antimicrobial activity. The clear zones formed around each bore were measured and average diameter of the inhibition zone was calculated and 
expressed in millimeter.

\section{Results and Discussion}

\subsection{Synthesis and Characterization of PDBIQ}

The spraying reagent, 6-pyridin-2-yl-5,6-dihydro-benzo [4,5]imidazo[1,2-c]quinazoline (PDBIQ) was synthesized by refluxing 2-(2-aminophenyl)-benzimidazol and pyridine-2-carboxaldehyde in equi-molar ratio in methanol viz. Scheme 1. The rearranged white product (PDBIQ) was obtained as the end-product. The structural analysis by spectroscopic tools and the X-ray crystallographic tools has confirmed this cyclic rearranged product. The solid state structure of PDBIQ has already been reported in the literature [9], and for that reason we are not describing the structure here, and the solid state structure of PDBIQ has been included in supplementary file as Figure S1.

\subsection{Detection of Amino Acids}

It is observed from Table $\mathbf{1}$ that detection limits obtained after uses of PDBIQ are very low in both cases before heating $(0.1-2.0 \mu \mathrm{g})$ and after heating $(0.05-1.0 \mu \mathrm{g})$ and various distinguishable colors were produced. Sometimes the detection limit is same before and after heating and in other cases it is somewhat different. It should be noted that identification of amino acids by ninhydrin is in practice difficult, in spite of the high sensitivity of ninhydrin. So the new spray reagent unable to differentiate the amino acids by color reaction. The mechanism of the color formation is still uncertain, but we may assume that carboxylic group of aminoacids first condensed with PDBIQ (heating at $90^{\circ} \mathrm{C}$ for $10 \mathrm{~min}$ ) to form a carbamide type intermediates which form charge transfer complexes with ninhydrin.

\subsection{Determination of Equilibrium Binding Constant}

The equilibrium binding constant of PDBIQ with different amino acids was given in Table 2 . The values are quite high. This high value indicates that there are some interaction between PDBIQ and amino acids through charge transfer transition. The Job's plot Figure 3 shows the maximum 1:1 adduct formation which confirms the ratio of adduct formation between ligand and amino acids during charge transfer transition.

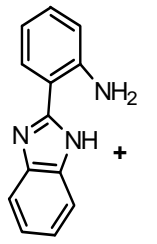<smiles>O=Cc1ccccn1</smiles>

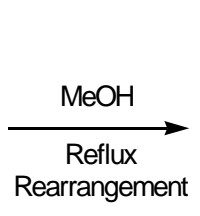<smiles>c1ccc(C2Nc3ccccc3-c3nc4ccccc4n32)nc1</smiles>

PDBIQ
Table 2. Equilibrium binding constants (k) of the molecular complexes between organic reagent and amino acids at $\mathbf{p H}$ 8.0 (phosphate buffer) at $25^{\circ} \mathrm{C}$.

\begin{tabular}{cc}
\hline Amino acids & $\mathrm{k}\left[\mathrm{dm}^{3} \cdot \mathrm{mole}^{-1}\right]$ \\
\hline L-Glycine & $1.25 \times 10^{6}$ \\
L-Alanine & $1.32 \times 10^{6}$ \\
L-Valine & $0.89 \times 10^{6}$ \\
L-Leucine & $5.47 \times 10^{6}$ \\
L-Isoleucine & $3.94 \times 10^{6}$ \\
L-Serine & $2.56 \times 10^{6}$ \\
L-Threonine & $1.66 \times 10^{6}$ \\
L-Aspartic acid & $0.72 \times 10^{6}$ \\
L-Aspargine & $1.21 \times 10^{6}$ \\
L-Glutamic acid & $3.40 \times 10^{6}$ \\
L-Glutamine & $2.72 \times 10^{6}$ \\
L-Lysine & $1.72 \times 10^{6}$ \\
L-Histidine & $5.40 \times 10^{6}$ \\
L-Arginine & $3.34 \times 10^{6}$ \\
L-Phenyl alanine & $1.53 \times 10^{6}$ \\
L-Tyrosine & $0.86 \times 10^{6}$ \\
L-Tryptophan & $1.87 \times 10^{6}$ \\
L-Cysteine & $0.79 \times 10^{6}$ \\
L-Cystine & $8.52 \times 10^{6}$ \\
L-Methionine & $8.89 \times 10^{6}$ \\
L-Proline & $5.23 \times 10^{6}$ \\
L-Hydroxy proline & $4.04 \times 10^{6}$ \\
\hline & \\
\hline
\end{tabular}

\subsection{Use of the Method for TLC Detection of the Amino Acids Present in $A$. excelsa Seed Protein}

It was found that spraying with a $0.01 \%$ solution of 6pyridin-2-yl-5,6-dihydro-benzo[4,5]imidazo[1,2-c]quinazoline (PDBIQ) in ethanol combined with spraying with $0.25 \%$ ninhydrin solution in acetone enabled detection of fourteen amino acids-arginine, isoleucine, glutamine, lysine, asparagine, phenylalanine, serine, alanine, glutamic acid, valine, aspartic acid, leucine, glycine, and proline even at low concentration of the amino acids. The results were also agreement with the respective $R_{F}$ values of the acids.

\subsection{Inhibitory Test with PDBIQ}

Antimicrobial test of PDBIQ was checked using cup plate method and the observed results of the inhibitory test performed with the reagent has been tabulated in Table 3 . Here, the diameter of inhibition zone for the organisms in presence of PDBIQ is significantly greater than that of the corresponding controlled replicate experiment. This study indicates that the compound has profound activity against the test organisms. 


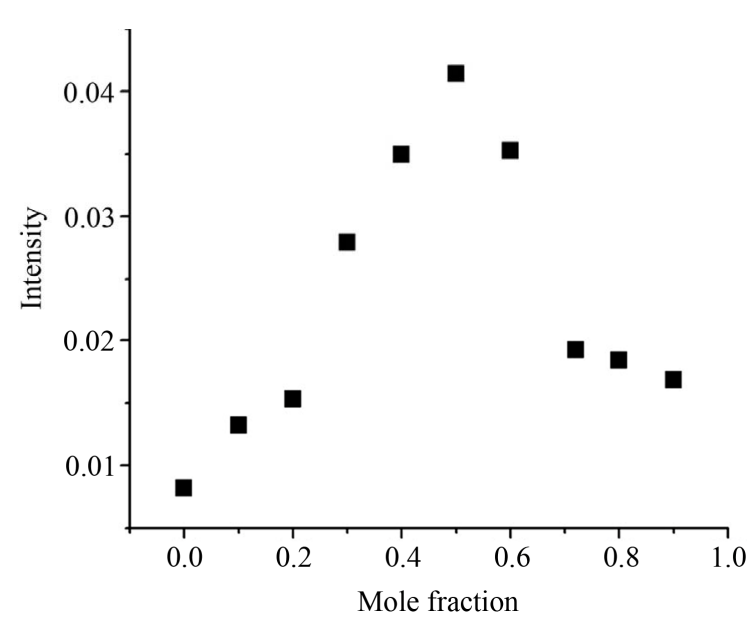

Figure 3. Job's plot analysis showing maximum emissionat 1:1 ratio [PDBIQ:Cysteine].

Table 3. Bioactivity test ${ }^{*}$ of PDBIQ.

\begin{tabular}{ccccc}
\hline Organism & Bacillus subtilis Bacillus sp. & E. coli & Salmonella sp. \\
\hline Control (EtOH) & 10 & 10 & 7 & 7 \\
PDBIQ & 14 & 15 & 11 & 10 \\
\hline
\end{tabular}

*Values are diameter of inhibition zone (mm).

\section{Conclusion}

This newly designed quinazoline based spraying reagent, PDBIQ has been established to detect twenty two amino acids on thin-layer chromatography plates producing various distinguishable colors with amino acids with a low detection limits. The binding ability of PDBIQ with amino acids has also been estimated by determining the binding constants $(\mathrm{k})$ spectroscopically and these values $(\mathrm{k})$ are significantly higher than those reported earlier. This reagent has also shown the significant inhibitory action against some gm $(+\mathrm{ve})$ and gm $(-\mathrm{ve})$ bacterial organisms.

\section{Acknowledgements}

Financial assistance from the Department of Science and Technology (DST), New Delhi, India, is gratefully acknowledged. S. Sen wishes to deeply acknowledge Dr. P. Chattopadhyay, B.U. for his support and constant encouragement.

\section{REFERENCES}

[1] S. Laskar and S. Lahiri, "An Account on Color Reagents for Detection of Amino Acids and Interaction of Metal Ions with Some Non-Conventional Seed Proteins," In: G. Brahmachari, Ed., Natural Products: Chemistry, Biochemistry and Pharmacology, Narosa Publishing House Pvt.
Ltd., New Delhi, 2009, pp. 676-702.

[2] V. Alagarsamy, V. R. Solomon, M. Murugan, R. Sankaranarayanan, R. Periyasamy and R. Deepa, "Synthesis of 3-(2-Pyridyl)-2-substituted-quinazolin-4(3H)-ones as New Analgesic and Anti-Inflammatory Agents," Biomedicine \& Pharmacotherapy, Vol. 62, No. 7, 2008, pp. 454-461. doi:10.1016/j.biopha.2006.10.003

[3] R. Rohini, K. Shanker, P. M. Reddy, A. Hu and V. Ravinder, "Anti Microbial Study of Newly Synthesized 6Substituted Indolo[1,2-c]Quinazolines," European Journal of Medicinal Chemistry, Vol. 41, No. 28, 2010, pp. 1200-1205. doi:10.1002/chin.201028163

[4] G. M. Higa and J. Abraham, "Lapatinib in the Treatment of Breast Cancer," Expert Review of Anticancer Therapy, Vol. 7, No. 9, 2007, pp. 1183-1192. doi:10.1586/14737140.7.9.1183

[5] H. R. Mahler and E. H. Cordes, "Basic Biological Chemistry," Harper and Row, New York, 1968.

[6] C. Haworth and J. G. Heathcote, "The Direct Determination of Amino Acids on Thin-Layer Chromatograms by Densitometry," Biochemistry Journal, Vol. 114, No. 3, 1969, pp. 667-668. doi:10.1016/S0021-9673(00)99169-6

[7] K. Lorentz and B. Flatter, "Staining of Amino Acids with Benzoquinone in Paper Chromatography," Analalytical Biochemistry, Vol. 38, No. 2, 1970, pp. 557-559. doi:10.1007/s007260170027

[8] B. Basak and S. Laskar, "Spray Reagents for the Detection of Amino-Acids on Thin-Layer Plates," Talanta, Vol. 37, No. 11, 1990, pp. 1105-1106. doi:10.1016/0039-9140(90)80163A

[9] S. Laskar, U. Bhattacharya and B. Basak, "Modified Ninhydrin Spray Reagent for the Identification of Amino Acids on Thin-Layer Chromatography Plates," Analyst Vol. 116, No. 6, 1991, pp. 1105-1106. doi:10.1039/an9911600625

[10] T. D. Samanta and S. Laskar, "New Reagent for Detection of Amino Acids on TLC Plates," Journal of Planar Chromatography, Vol. 19, No. 109, 2006, pp. 252-254. doi:10.1556/JPC.19.2006.3.17

[11] A. M. Pyle, J. P. Rehmann, R. Meshoyrer, C. V. Kumar, N. J. Turro and J. K. Barton, "Mixed-Ligand Complexes of Ruthenium(II): Factors Governing Binding to DNA," Journal of American Chemical Socity, Vol. 111, No. 8, 1989, pp. 3051-3058. doi:10.1021/ja00190a046

[12] S. Bhattacharya, S. Bhattacharya (Banerjee), K. Ghosh, S. Basu, M. Banerjee, "Study of Electron Donor-Acceptor Complex Formation of o-Chloranil with a Series of Phosphine Oxides and Tri- n-Butyl Phosphate by the Absorption Spectrometric Metric method," Journal of Solution Chemistry, Vol. 35, No. 4, 2006, pp. 519-539. doi:10.1007/s10953-005-9013

[13] R. Cruickshank, J. P. Duguid, B. P. Marmion and R. H. A. Swain, "Medical Microbiology," 12th Edition, Edward Arnold Publishers, London, Vol. II, 1975. 


\section{Supplementary Information}

\section{X-Ray crystal structure analysis}

Diffraction data were measured for 6-pyridin-2-yl-5, 6dihydro-benzo [4,5] imidazo [1,2-c] quinazoline (PDBIQ) with $\operatorname{MoK}_{\alpha}(\lambda=0.71073 \AA)$ radiation at $293 \mathrm{~K}$. The crystals were positioned at $70 \mathrm{~mm}$ from the image plate and 95 frames were measured at $2^{\circ}$ intervals with a counting time of $2 \mathrm{~min}$. Data analysis was carried out with the XDS program. The structure was solved using direct methods with the SHELXS97 program. The non-hydrogen atoms were refined with anisotropic thermal parameters. The hydrogen atoms bonded to carbon were included in geometric positions and given thermal parameters equivalent to 1.2 times those of the atom to which they were attached. The hydrogen atoms attached to the water molecules were located in difference Fourier maps and refined with distance constraints. An empirical absorption correction was carried out on 1 using the DIFABS program. Refinement on all four structures was carried out with a full matrix least squares method against $\mathrm{F}^{2}$ using SHELXL97.

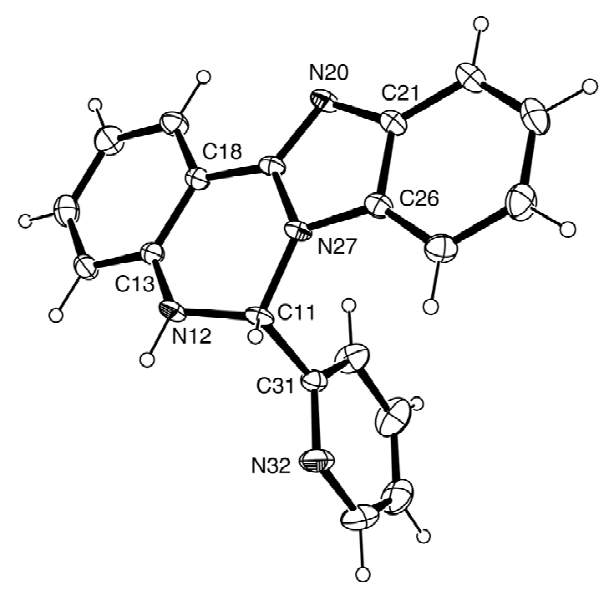

Figure S1. The structure of 6-pyridin-2-yl-5,6-dihydro-benzo $[4,5]$ imidazo[1,2-c]quinazoline (PDBIQ) with ellipsoids at $25 \%$ probability. 